\title{
Dovzetnost bub plodove vinske mušice (Drosophila suzukii (Matsumura, 1931)) za okužbo z entomopatogenimi glivami
}

\author{
Jaka RAZINGER $^{1 *}$, Katja FINK ${ }^{2}$, Ana KERIN ${ }^{3}$, Špela MODIC ${ }^{4}$, Gregor UREK ${ }^{1}$
}

Received December 22, 2016; accepted Janury 18, 2017.

Delo je prispelo 22. decembra 2016, sprejeto 18. januarja 2017.

\section{IZVLEČEK}

Zatiranje plodove vinske mušice (PVM) (Drosophila suzukii (Matsumura, 1931), Diptera, Drosophilidae) je težavno, ker ima vrsta izjemen razmnoževalni potencial, je polifagna in ima ostro nazobčano leglico, s katero lahko predre povrhnjico zdravih plodov, v katere nato izleže jajčeca. Poleg tega se odrasle žerke lahko zabubijo $\mathrm{v}$ tleh, kjer so zavarovane pred insekticidi. Naša hipoteza je bila, da bodo talne glive, ki so patogene za žuželke, znatno zmanjšale izleganje mušic iz okuženih bub PVM. Bube PVM smo okuževali $z$ več entomopatogenimi in talnimi glivami: a) $\mathrm{v}$ substratu, okuženim s konidiji gliv, b) $\mathrm{z}$ neposrednim nanosom suspenzije gliv na bube ter c) z namakanjem bub v suspenzijo gliv. Gliva Metarhizium brunneum Petch izolat H.J.S. 1154 je značilno zmanjšala izleganje PVM v okuženem substratu, bioinsekticid Naturalis (na podlagi entomopatogene glive Beauveria bassiana (Bals.-Criv.) Vuill.) pa v poskusih neposredne izpostavitve. Poskus namakanja bub v suspenzijo gliv, s katerim smo želeli določiti $\mathrm{IC}_{50}$ izleganja bub, je bil neuspešen. Sklepamo, da je razvojni stadij bube PVM prekratek, da bi glive izrazito vplivale na izleganje odraslih osebkov PVM. Skladno $\mathrm{z}$ našimi rezultati in objavljeno literaturo, bi bilo smiselno preučiti potencial entomopatogenih gliv $\mathrm{v}$ biotičnem varstvu neposredno na odraslih osebkih PVM.

Ključne besede: biotično varstvo rastlin; entomopatogene glive; jagodičevje; škodljivci; talne glive; virulenca; žuželke

\section{ABSTRACT \\ SUSCEPTIBILITY OF SPOTTED WING DROSOPHILA (Drosophila suzukii (Matsumura, 1931)) PUPAE TO ENTOMOPATHOGENIC FUNGI}

Spotted wing drosophila (Drosophila suzukii (Matsumura, 1931), Diptera, Drosophilidae) management is difficult mainly because of its short generation time, polyphagy and serrated ovipositor, but also because its larvae can pupate in the orchard soil and are thus protected from insecticide applications. We hypothesized that insect-pathogenic soil fungi could successfully infect Drosophila suzukii pupae in soil environment. We tested several entomopathogenic or soil fungi against pupae in a) conidia-spiked soil, b) via direct applications of conidia, and c) by dipping pupae into conidial suspensions. Metarhizium brunneum Petch strain H.J.S. 1154 significantly reduced fly emergence in conidia spiked soil and bioinsecticide Naturalis (based on entomopathogenic fungus Beauveria bassiana (Bals.-Criv.) Vuill. in direct exposure tests. Our attempt to determine $\mathrm{IC}_{50}$ of pupal hatching rate by dipping D. suzukii pupae into conidial suspensions was unsuccessful. We conclude that the pupal stage is probably too brief to allow entomopathogens to cause a significant reduction of fly emergence. According to our results and published articles, the fungal biocontrol potential would probably best be evaluated in spray applications against adult flies.

Key words: biological control; entomopathogenic fungi; insect-pathogenic soil fungi, insect; organic; pest; soft fruit; virulence

\footnotetext{
1 dr., Oddelek za varstvo rastlin, Kmetijski inštitut Slovenije, Hacquetova ulica 17, 1000 Ljubljana, Slovenija. Korespondenca: e-mail jaka.razinger@kis.si

2 univ. dipl. prof. biol. kem., Bašelj 13, 4205 Preddvor, Slovenija

3 univ. dipl. biol., Bučerca 17, 8270 Krško, Slovenija

4 mag., Oddelek za varstvo rastlin, Kmetijski inštitut Slovenije, Hacquetova ulica 17, 1000 Ljubljana, Slovenija
} 


\section{UVOD}

Plodova vinska mušica (PVM) (Drosophila suzukii (Matsumura, 1931), Diptera, Drosophilidae) izvira iz Azije in je od 1. 2008 zastopana v Severni Ameriki in Evropi, kjer povzroča škodo na jagodičevju (Cini in sod., 2014). Od ostalih sorodnih vrst vinskih mušic, ki se prehranjujejo na gnijočih in poškodovanih plodovih, se samice PVM razlikujejo po ostro nazobčani leglici, s katero lahko samice odlagajo jajčeca $\mathrm{v}$ nepoškodovane zoreče plodove in povzročijo večje izgube pridelka (Lee in sod., 2011). V domači strokovni literaturi sta o škodljivcu in možnih načinih njegovega zatiranja že pisala Bohinčeva in Trdan (2014).

PVM se razmnožuje hitro in ima skozi celo rastno dobo na razpolago številne gostiteljske rastline, zato je njeno zatiranje oteženo. Poleg tega lahko dorasle žerke zapustijo plod in se zabubijo v tleh sadovnjaka, kjer so varne pred insekticidi (Cuthbertson in sod., 2014a). Proučevanih je bilo že več strategij varstva $v$ nasadih ameriških borovnic, jagodnjaka, malinjaka (e.g. Bruck in sod., 2011; Van Timmeren and Isaacs, 2013) in drugih sadnih vrst, toda pri ekološki pridelavi sadja je raba insekticidov močno omejena, poleg tega njihova raba negativno vpliva na koristne organizme. Več raziskav v svetu je bilo usmerjenih v proučevanje parazitoidov in plenilcev (Chabert in sod. 2012; Gabarra in sod. 2015; Rossi Stacconi in sod. 2015; Woltz in sod. 2015), entomopatogenih ogorčic (Cuthbertson in sod., 2014b; Gargani in sod., 2013; Woltz in sod., 2015) in entomopatogenih gliv (Naranjo-Lázaro in sod., 2014) $z$ namenom učinkovitega biotičnega zatiranja PVM. V nobeni od omenjenih raziskav pa niso neposredno preizkušali vpliv izolatov entomopatogenih gliv (EPF) na razvojni stadij bube PVM.

Naša hipoteza je bila, da lahko entomopatogene glive uspešno okužijo bube PVM $\mathrm{v}$ testnem substratu. Znano pa je, da so lahko, poleg entomopatogenih gliv, tudi talne glive patogene za žuželke, kar smo že dokazali na zgledu kapusove muhe Delia radicum (Linnaeus, 1758) (Razinger in sod., 2014a, b). Cilji raziskave so bili določiti zmanjšanje izleganja mušic a) zaradi posredne, substratne, izpostavitve glivam in b) neposredne izpostavitve glivam, ter c) določiti inhibicijo izleganja $\left(\mathrm{IC}_{50}\right)$ bub prek namakanja bub $\mathrm{v}$ suspenziji konidijev različnih talnih in entomopatogenih gliv.

\section{MATERIALI IN METODE}

\subsection{Nanos gliv in bioinsekticidov}

Preskušali smo glive Metarhizium brunneum Petch (izolata H.J.S. 1154 in 1868), Trichoderma atroviride Bissett (izolat 1873), Clonostachys rosea (Link) Schroers (izolat 1884), in Beauveria bassiana (Bals.-Criv.) Vuill. (izolata 2121 and 2122). V poskusih smo konidije dodajali testnemu substratu v vodni suspenziji. Glive smo gojili ter preverili viabilnost konidijev, kot je opisano $\mathrm{v}$ Razinger in sod. (2014b). Bioinsekticid Laser 240 SC (a.s. spinosad, 22,75 \% w/w, Dow Agrosciences, Dunaj, Avstrija) smo uporabili kot pozitivno kontrolo. Bioinsekticid Naturalis (a.s. B. bassiana, 2,3 x $10^{7} \mathrm{CFU} \mathrm{ml}^{-1}$, Andermatt biocontrol AG, Grossdietwil, Švica) smo uporabili kot referenčni biotični pripravek. Neionski detergent Tween $80(0,1 \%)$ smo uporabili kot negativno kontrolo.

\subsection{Gojenje plodove vinske mušice}

PVM smo gojili v $30 \times 30 \times 30 \mathrm{~cm}$ plastičnih insektarijih $\mathrm{v}$ komori $\mathrm{v}$ nadzorovanih razmerah: dan:noč $14: 10$ h pri $21{ }^{\circ} \mathrm{C}$ in $77 \pm 3 \% \mathrm{RH}$. Mušice so imele na razpolago vodovodno vodo ter umetno hrano (20 g agarja, 20 g sladkorja, 10 g pšenične moke, $50 \mathrm{~g}$ suh pekovski kvas, $500 \mathrm{ml}$ vodovodne vode, $400 \mathrm{~g}$ naribanih ekoloških jabolk, $500 \mathrm{ml}$ ekološkega jabolčnega soka, $50 \mathrm{ml}$ jabolčnega kisa in $4 \mathrm{~g}$ nipagina (methyl 4-hydroxybenzoate, Sigma-Aldrich)), kamor so legle jajčeca in v kateri so se razvijale ličinke.

\subsection{Zasnova poskusov}

2.3.1 Substratna izpostavitev bub plodove vinske mušice

Štiristo gramom na zraku posušenega šotnega komercialnega substrata za presajanje 
(Tonsubstrat, Klasmann-Deilmann GmbH, Nemčija) smo dodali $40 \mathrm{ml}$ suspenzije konidijev in $40 \mathrm{ml}$ sterilne demineralizirane vode. Substrat s konidiji smo temeljito premešali s sterilno lopatico $\mathrm{v}$ plastični posodi, da smo dobili končno koncentracijo $4 \times 10^{6}$ živih konidijev $\mathrm{g}^{-1}$ zračnosuhega substrata. 40-gramske alikvote substrata $\mathrm{s}$ konidiji smo dodali v posamezne $250 \mathrm{ml}$ poskusne posodice. V vsako posodico smo dodali pet 1-3 dni starih bub PVM. Pokrove testnih posod smo preluknjali z iglo. Poskus smo izvajali v enakih razmerah kot smo gojili mušice (opisano zgoraj). Vsak dan do osem dni po okužbi smo beležili število izleglih mušic. Neizlegle bube smo prestavili na vodni agar (1\%) in po sedmih dneh določili stopnjo okužbe z glivami.

\subsubsection{Neposredna izpostavitev bub plodove vinske mušice}

Pet 1-3 dni starih bub PVM smo dali v posamezno jamico na multi-plošči $\mathrm{s} \quad 6$ jamicami. $50 \mu 1$ suspenzije konidijev s koncentracijo $1 \times 10^{8}$ živih konidijev $\mathrm{ml}^{-1}$ smo odpipetirali neposredno na bube. Vsak dan do osem dni po okužbi smo beležili število izleglih muh. Neizlegle bube smo prestavili na vodni agar (1\%) in po sedmih dneh določili stopnjo okužbe z glivami.

\subsubsection{Določanje $50 \%$ inhibicije izleganja bub $\left(\mathrm{IC}_{50}\right)$}

Deset 1-3 dni starih bub PVM smo namočili v suspenzije konidijev, 0,1 \% Naturalis, ali Tween $80(0,1 \%)$ kot negativno kontrolo, za $30 \mathrm{~s}$, ob sočasnem rahlem mešanju. Preskušali smo naslednje koncentracije suspenzij konidijev: $10^{8}$, $10^{6}, 10^{5}, 10^{4}, 10^{2}$ in 0 živih konidijev $\mathrm{ml}^{-1}$. Po namakanju smo neadsorbirane suspenzije konidijev ali ostale testne tekočine odstranili tako, da smo izpostavljene bube prestavili na sterilne papirne brisače. Po 10 izpostavljenih bub smo prestavili v posamezno jamico na multi-plošči $s \quad$ šestimi jamicami. V vsako jamico smo dodali $1 \mathrm{~g}$ umetne hrane. Umetno hrano smo zamenjali po 7 dneh, da smo preprečili razvoj naslednjega rodu PVM. Negativna kontrola je bila izvedena $v$ šestih ponovitvah, ostali postopki pa $\mathrm{v}$ treh. Eno ponovitev je predstavljalo 10 bub $\mathrm{v}$ posamezni jamici. Poskus smo opazovali $0,2,3,4,7,10$ in 16 dni po izpostavitvi (PI) in beležili število izleglih mušic.

\subsection{Analiza podatkov}

Podatke iz poskusov substratne in neposredne izpostavitve bub PVM smo analizirali za normalnost razporeditve $\mathrm{z}$ D'Agostino-Pearson omnibus K2 testom. Iz teh podatkov smo izračunali parameter 'dolgoživost mušic', kot povprečje vsote živih mušic opaženih $\mathrm{v}$ vseh ponovitvah $\mathrm{v}$ vseh dneh opazovanj poskusov. Ta parameter nam je služil kot ocena posrednega vpliva obravnavanj na mušice (odrasle osebke). Statistično značilnost razlik med obravnavanji in negativno kontrolo smo izračunali $\mathrm{z}$ dvosmerno analizo variance s faktorjema 'čas po izpostavitvi' in ' obravnavanje' ter Bonferronijevim post-testom. Kumulativno stopnjo izleganja smo obdelali $\mathrm{Z}$ enosmerno analizo variance in Dunnettovim posttestom. Podatke iz poskusa Določanje $\mathrm{IC}_{50}$ smo analizirali $\mathrm{z}$ dvosmerno analizo variance $\mathrm{z}$ dejavnikoma 'koncentracija konidijev' in 'čas po izpostavitvi' ter Bonferronijevimi post-testi (Gaddum, 1948; Motulsky, 1995). Razlika med obravnavanji in negativno kontrolo je bila značilna pri pogoju $\mathrm{P}<0,05$, in je označena $\mathrm{v}$ grafih oz. $\mathrm{v}$ tabeli z zvezdico (*). Śtevilo neodvisnih ponovitev poskusov in ponovitve $\mathrm{v}$ posameznem poskusu so navedene v naslovih grafov oz. tabele. Statistične analize smo opravili s programom GraphPad Prism 5.00 (GraphPad Software, Inc., La Jolla, CA, ZDA).

\section{REZULTATI}

\subsection{Substratna izpostavitev bub plodove vinske mušice}

$\mathrm{Na}$ število živih mušic $\mathrm{v}$ poskusu substratne izpostavitve bub je značilno vplival čas izpostavitve $\left(\mathrm{F}_{8,942}=389 ; \mathrm{P}<0.0001\right)$ in interakcija dejavnikov 'čas izpostavitve' in 'obravnavanje' $\left(\mathrm{F}_{64,942}=4,79 ; \mathrm{P}<0.0001\right)$, medtem ko samo 'obravnavanje' ni imelo značilnega vpliva $\left(\mathrm{F}_{8,942}=1,6 ; \mathrm{P}=0,1210\right)$. Bonferronijev post-test je pokazal značilno večje število živih mušic $v$ kontrolnem obravnavanju $\mathrm{V}$ primerjavi $\mathrm{Z}$ obravnavanjem B. bassiana (seva 2121 in 2122) na tretji dan in pri sevu 2122 tudi četrti dan po izpostavitvi (PI). Značilno manj živih mušic $\mathrm{v}$ 
primerjavi s kontrolo je bilo v skupinah okuženih $\mathrm{z}$ glivama $C$. rosea in $B$. bassiana (2121) ter pripravkom Naturalis šesti dan PI, ter glivama $M$. brunneum (1868) in B. bassiana (2121 in 2122) ter pripravkom Naturalis sedmi dan PI (Slika 1). Najbolj patogen izolat glive (M. brunneum 1154) je povzročil $15 \%$ (značilno), bioinsekticid
Naturalis pa $5 \%$ zmanjšanje (neznačilno) celokupnega izleganja mušic $\mathrm{v}$ primerjavi $\mathrm{s}$ kontrolno skupino. Obravnavanja niso značilno vplivala na parameter 'dolgoživost mušic' (Tabela 1). Največ neizleglih in okuženih bub smo opazili $\mathrm{v}$ skupinah okuženih z glivama $M$. brunneum (1154 in 1868) in B. bassiana (2121 in 2122).

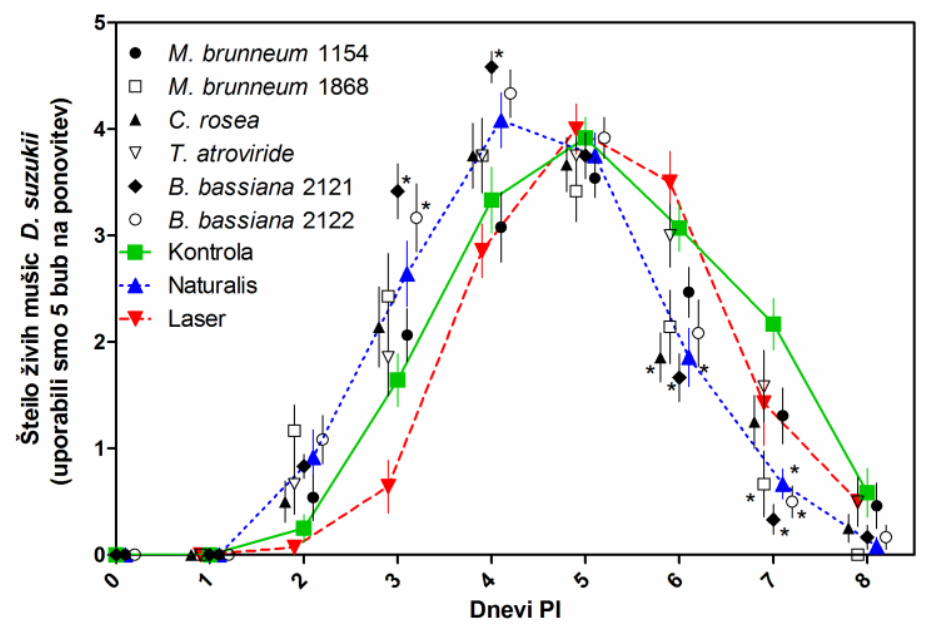

Slika 1: Število živih mušic vrste $D$. suzukii, ki so se izlegle iz bub, vstavljenih v substrat, ki je bil okužen z različnimi glivami, ali obdelan z bioinsekticidom, v odvisnosti od časa po izpostavitvi. Zvezdica (*) označuje značilno razliko od kontrolnih vzorcev $(\mathrm{P}<0,05)$. Predstavljena so povprečja \pm standardna napaka. Uporabili smo pet bub na ponovitev. Število ponovitev (N), združenih iz dveh poskusov, je bilo 14. Podatkovne točke na grafu smo zamaknili do $\pm 0,2$ enote za preprečevanje prekrivanja. Naturalis - bioinsekticid na podlagi glive Beauveria bassiana izolat ATCC 74040. Laser 240 SC - bioinsekticid na podlagi aktivne snovi spinosad; PI - po izpostavitvi oz. okužbi.

Figure 1: The number of living D. suzukii flies emerged from pupae placed into soil inoculated with different fungi or treated with bioinsecticide. Asterisk $(*)$ denotes a significant difference from control samples $(\mathrm{P}<0.05)$. Data presented are means \pm standard error. Five pupae per replicate were used. Number of replicates $(\mathrm{N})$ pooled from two experiments was 14. Data points on the graph were nudged up to \pm 0.2 units to prevent overlapping. Naturalis - bioinsecticide based on Beauveria bassiana isolate ATCC 74040. Laser 240 SC- insecticide based on spinosad; Dnevi PI - days post infection.

\subsection{Neposredna izpostavitev bub plodove vinske mušice}

$\mathrm{Na}$ število živih mušic $\mathrm{v}$ poskusu neposredne izpostavitve sta značilno vplivala dejavnika 'obravnavanje' $\left(\mathrm{F}_{8,891}=9,40 ; \mathrm{p}<0,0001\right)$ in 'čas po izpostavitvi' $\left(\mathrm{F}_{8,891}=184 ; \mathrm{p}<0,0001\right)$, hkrati pa tudi njuna interakcija $\left(\mathrm{F}_{64,891}=2,12 ; \mathrm{p}<0,0001\right)$. Bonferronijev post-test je pokazal značilno manj preživelih mušic, $\mathrm{v}$ primerjavi $\mathrm{s}$ kontrolo, $\mathrm{v}$ skupinah okuženih z glivo $T$. atroviride četrti dan PI, z bioinsekticidom Laser 240 SC peti in šesti dan PI in pripravkom Naturalis šesti dan PI (Slika 2). Obravnavanja so značilno vplivala na parameter 'dolgoživost mušic' pri testu neposredne izpostavljenosti $\left(\mathrm{F}_{8,99}=12,2 ; \mathrm{p}<0,0001\right)$. Najbolj patogen izolat (M. brunneum 1154) je povzročil 8 $\%$ (neznačilno), Naturalis pa $21 \%$ (značilno) zmanjšanje celokupnega izleganja mušic $\mathrm{v}$ primerjavi s kontrolno skupino. Skupine žuželk, ki so bile okužene $\mathrm{z}$ glivo M. brunneum (1154 in 1868), ter pripravki Naturalis in Laser 240 SC, so imele značilno manjši parameter 'dolgoživost mušic', v primerjavi s kontrolo (Tabela 1). Največ neizleglih okuženih bub smo opazili v skupinah, okuženih z glivami M. brunneum (1154 in 1868), C. rosea, B. bassiana (2121) in pripravkom Naturalis. 


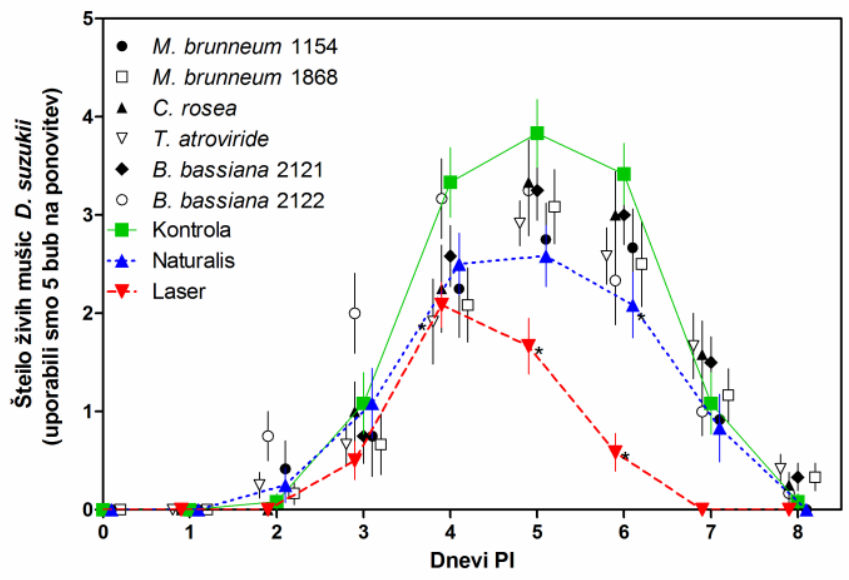

Slika 2: Število živih mušic vrste $D$. suzukii, ki so se izlegle iz bub neposredno okuženih z različnimi glivami ali obdelanih z bioinsekticidom, v odvisnosti od časa po izpostavitvi. Zvezdica $\left(^{*}\right)$ označuje značilno razliko od kontrolnih vzorcev $(\mathrm{P}<0,05)$. Predstavljena so povprečja \pm standardna napaka. Uporabili smo pet bub na ponovitev. Število ponovitev $(\mathrm{N})$, združenih iz dveh poskusov, je bilo 12. Podatkovne točke na grafu smo zamaknili do $\pm 0,2$ enote za preprečevanje prekrivanja. Naturalis - bioinsekticid na osnovi glive Beauveria bassiana izolat ATCC 74040. Laser 240 SCbioinsekticid, ki temelji na aktivni učinkovini spinosad; PI - po izpostavitvi oz. okužbi.

Figure 2: The number of living $D$. suzukii flies emerged from pupae directly infected with different fungi or treated with bioinsecticide. Asterisk $\left({ }^{*}\right)$ denotes a significant difference from control samples $(\mathrm{P}<0.05)$. Data presented are means \pm standard error. Five pupae per replicate were used. Number of replicates $(\mathrm{N})$ pooled from two experiments was 12. Data points on the graph were nudged up to \pm 0.2 units to prevent overlapping. Naturalis - bioinsecticide based on Beauveria bassiana isolate ATCC 74040. Laser 240 SC - insecticide based on spinosad; Dnevi PI - days post infection.

Tabela 1: Parameter 'dolgoživost mušic', izračunan kot povprečje vsote živih mušic v vseh ponovitvah v vseh dneh opazovanj poskusov. Zvezdica $(*)$ označuje značilno razlikovanje od negativne kontrole $(\mathrm{P}<0,05)$. Predstavljena so povprečja \pm standardna napaka. Uporabili smo pet bub na ponovitev. Število ponovitev $(\mathrm{N})$, združenih iz dveh poskusov, je bilo $14 \mathrm{v}$ poskusu substratne izpostavitve in $12 \mathrm{v}$ poskusu neposredne izpostavitve.

Table 1: Parameter Fly longevity, calculated as the replicate average of the sum of living flies observed at all observation days. Asterisk $(*)$ denotes a significant difference from control samples $(\mathrm{P}<0.05)$. Data presented are means \pm standard error. Five pupae per replicate were used. Number of replicates $(\mathrm{N})$ pooled from two experiments was 14 in soil test and 12 in direct exposure test.

\begin{tabular}{|c|c|c|}
\hline Obravnavanje & Substratna izpostavitev & Neposredna izpostavitev \\
\hline & Dolgoživost mušic (a.u.) & Dolgoživost mušic (a.u.) \\
\hline M. brunneum (1154) & $13,5 \pm 0,68$ & $9,8 \pm 0,83^{*}$ \\
\hline M. brunneum (1868) & $13,8 \pm 0,81$ & $10,0 \pm 0,59 *$ \\
\hline C. rosea (1884) & $13,9 \pm 0,81$ & $11,4 \pm 0,71$ \\
\hline T. atroviride (1873) & $15,3 \pm 0,72$ & $10,4 \pm 0,73$ \\
\hline B. bassiana (2121) & $14,8 \pm 0,45$ & $11,5 \pm 0,90$ \\
\hline B. bassiana (2122) & $15,3 \pm 0,62$ & $12,7 \pm 0,75$ \\
\hline Kontrola & $14,9 \pm 0,70$ & $12,9 \pm 0,48$ \\
\hline Naturalis $^{\mathrm{a}}$ & $14,1 \pm 0,83$ & $9,3 \pm 0,67 *$ \\
\hline Laser $240 \mathrm{SC}^{\mathrm{b}}$ & $13,0 \pm 0,77$ & $4,8 \pm 0,39 *$ \\
\hline
\end{tabular}

${ }^{a}$ Bioinsekticid na podlagi glive Beauveria bassiana izolat ATCC 74040, uporabljen v priporočeni koncentraciji $0,1 \%(\mathrm{v} / \mathrm{v})$.

${ }^{\mathrm{b}}$ Bioinsekticid na podlagi spinosada $(22,75 \% \mathrm{~m} / \mathrm{m}$ aktivne učinkovine), uporabljen $\mathrm{v}$ priporočeni koncentraciji $0,1 \%(\mathrm{v} / \mathrm{v})$. 


\subsection{Določanje $50 \%$ inhibicije izleganja bub $\left(\mathrm{IC}_{50}\right)$}

$\mathrm{Na}$ število mušic, izleglih iz bub okuženih z glivo M. brunneum $1868 \mathrm{v}$ poskusu določanja $\mathrm{IC}_{50}$, je značilno vplivala 'koncentracija konidijev' $\left(\mathrm{F}_{6,119}=7,94 ; \mathrm{p}<0,0001\right)$ in 'čas po izpostavitvi' $\left(\mathrm{F}_{6,119}=380, \mathrm{p}<0,0001\right)$ ter njuna interakcija $\left(\mathrm{F}_{36,119}=2,41 ; \mathrm{P}=0,0002\right)$. Bonferronijevi post testi so pokazali značilno manj izleglih mušic $\mathrm{V}$ primerjavi s kontrolo $\mathrm{v}$ skupinah okuženih z $10^{2}$ $\mathrm{ml}^{-1}$ viabilnih konidijev glive M. brunneum 1868 ( $\mathrm{v}$ nadaljevanju konidijev) četrti dan PI, ter $\mathrm{v}$ skupinah okuženih z $10^{4}$ konidijev četrti, sedmi in 16. dan PI, $10^{5}$ konidijev četrti dan PI, $10^{6}$ konidijev četrti in 10 . dan PI in $10^{8}$ viabilnih konidijev $\mathrm{ml}^{-1}$ 16. dan PI (24\% zmanjšanje). Na število mušic, izleglih iz bub, okuženih z glivo $M$. brunneum $1868 \mathrm{v}$ poskusu določanja $\mathrm{IC}_{50}$, je prav tako značilno vplivala 'koncentracija konidijev' $\left(\mathrm{F}_{6,119}=3,61 ; \mathrm{p}=0,0026\right)$ in 'čas po izpostavitvi' $\left(\mathrm{F}_{6,119}=343, \mathrm{p}<0,0001\right)$, ne pa njuna interakcija $\left(\mathrm{F}_{6,119}=1,43 ; \mathrm{P}=0,0796\right)$. Okužba bub z $10^{8}$ viabilnimi konidiji glive $M$. brunneum $1868 \mathrm{ml}^{-1}$ je zmanjšalo število izleglih mušic za $8 \%$ 16. dan PI $\mathrm{v}$ primerjavi s kontrolno skupino. Število mušic, izleglih iz bub, okuženih $\mathrm{z}$ glivo $B$. bassiana (2121) v poskusu določanja $\mathrm{IC}_{50}$, je bilo odvisno od dejavnikov 'koncentracija konidijev' $\left(F_{6,119}=7,93 ; p<0,0001\right)$ in 'čas po izpostavitvi' $\left(\mathrm{F}_{6,119}=246 ; \mathrm{p}<0,0001\right)$ ter tudi njune interakcije $\left(\mathrm{F}_{36,119}=2,39 ; \mathrm{P}=0,0002\right)$. Bonferronijevi post testi so pokazali značilno manj izleglih mušic $\mathrm{v}$ primerjavi s kontrolo, kjer je bila koncentracija viabilnih konidijev $10^{6} \mathrm{ml}^{-1}$ četrti, sedmi, 10. in 16 . dan PI in pri koncentraciji $10^{8}$ viabilnih konidijev $\mathrm{ml}^{-1}$ četrti dan PI. Okužba bub z $10^{8}$ viabilnimi konidiji glive $B$. bassiana (2121) $\mathrm{ml}^{-1}$ je povzročilo 24 \% zmanjšanje števila izleglih mušic 16. dan PI $\mathrm{v}$ primerjavi s kontrolno skupino. Namakanje bub v $0,1 \%$ raztopino pripravka Naturalis je značilno vplivalo na izleganje mušic četrti dan PI. 16. dan PI je bilo 4 \% (neznačilno) manj izleglih mušic $\mathrm{v}$ obravnavanju s pripravkom Naturalis $\mathrm{v}$ primerjavi s kontrolo (Slika 3). 


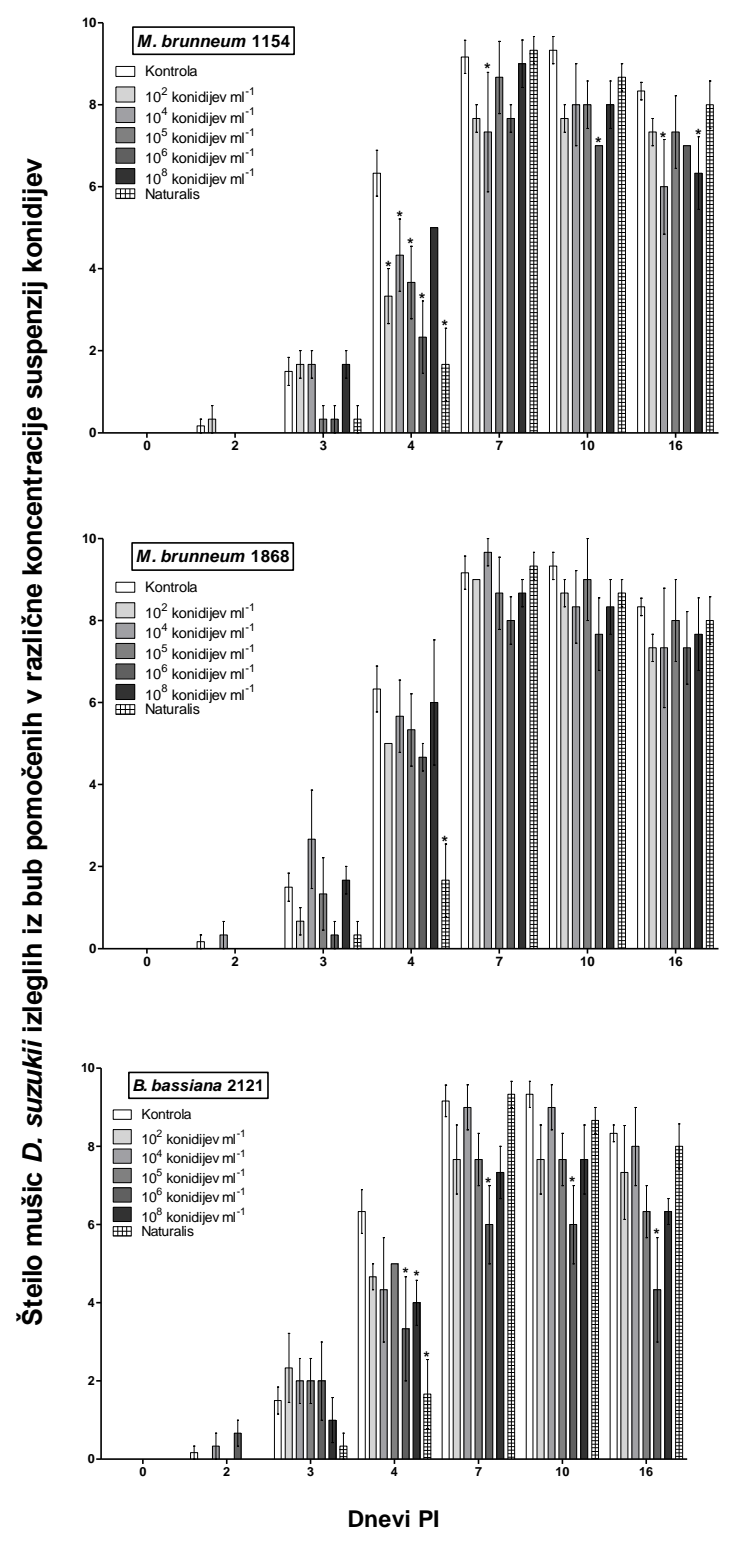

Slika 3: Število mušic vrste $D$. suzukii, izleglih iz bub, pomočenih v različnih koncentracijah konidijev ali obdelanih z bioinsekticidom, v odvisnosti od časa po izpostavitvi. Zvezdica $(*)$ označuje značilno razlikovanje od kontrolnih vzorcev $(\mathrm{P}<0,05)$. Predstavljena so povprečja \pm standardna napaka. Uporabili smo deset bub na ponovitev. Standardne napake so izračunane iz šestih ponovitev kontrolnih vzorcev in treh ponovitev pri ostalih obravnavanjih. Naturalis - bioinsekticid na osnovi izolata glive Beauveria bassiana ATCC 74040; PI - po izpostavitvi oz. okužbi.

Figure 3: The number of living $D$. suzukii flies emerged from pupae dipped into various concentrations of fungal conidia or treated with bioinsecticide. Asterisk $(*)$ denotes a significant difference from control samples $(\mathrm{P}<0.05)$. Data presented are means \pm standard error. Ten pupae per replicate were used. Error bars are drawn from 6 in control and 3 replicates in fungal treatments. Naturalis - bioinsecticide based on Beauveria bassiana isolate ATCC 74040. Dnevi PI - days post infection. 


\section{DISKUSIJA}

$\mathrm{V}$ poskusih posredne (substratne) in neposredne izpostavitve bub plodove vinske mušice (PVM; $D$. suzukii) smo ugotovili, da glive in bioinsekticida značilno vplivajo na izleganje bub $\mathrm{s}$ sočasnim pojavom mikoz na večini neizleglih bub (Slika 1, Slika 2, Tabela 1). Izpostavljenost glivam je, čeprav značilno, sorazmeroma malo zmanjšala število izleglih bub $\mathrm{V}$ poskusih $\mathrm{Z}$ okuženim substratom ter pri poskusih $\mathrm{z}$ neposredno izpostavitvijo (izolat glive M. brunneum 1154 je povzročil 15 in $8 \%$, Naturalis pa 5 in $21 \%$ zmanjšanje celokupnega izleganja mušic $\mathrm{v}$ poskusih $\mathrm{Z}$ okuženim substratom oziroma $\mathrm{V}$ poskusih $\mathrm{Z}$ neposredno izpostavitvijo). Naša hipoteza, da bodo talne glive iz rodov Clonostachys ali Trichoderma $\mathrm{v}$ poskusih substratne izpostavitve prekašale entomopatogene glive, je bila zavrnjena, saj je le dobro znana entomopatogena gliva M. brunneum (sev H.J.S. 1154) značilno zmanjšala izleganje mušic $v$ okuženem substratu. To gre morebiti pripisati kratkotrajnosti razvojnega stadija bube PVM, ki (entomopatogenim) glivam ne omogoča, da bi v takšnih razmerah dosegle želen učinek (Cini in sod., 2012).

Izpostavljenost glivam je imela tudi posreden vpliv na izlegle mušice, še posebej $\mathrm{v}$ poskusih $\mathrm{z}$ neposredno izpostavitvijo. Mušice, ki so se izlegle iz bub neposredno okuženih $\mathrm{z}$ izolatom glive $M$. brunneum (1154 in 1858) ali bioinsekticidoma Naturalis in Laser $240 \mathrm{SC}$, so imele značilno manjšo vrednost parametra 'dolgoživost mušic' (Tabela 1). To je lahko povezano $\mathrm{z}$ nanosom velikega števila konidijev na posamezno bubo, saj so bili konidiji v poskusu neposredne izpostavitve naneseni neposredno na bube, $\mathrm{v}$ primerjavi $\mathrm{s}$ poskusom substratne izpostavitve, kjer nismo opazili značilnega vpliva na parameter 'dolgoživost mušic'. Zanimivo pa smo $\mathrm{v}$ poskusu substratne izpostavitve opazili, da je izpostavitev bub nekaterim sevom gliv premaknila krivuljo izleganja $\mathrm{v}$ levo, torej so se mušice hitreje razvile in izlegle, a tudi hitreje poginile $\mathrm{v}$ primerjavi $\mathrm{z}$ mušicami v kontrolni skupini (npr. izolata glive $B$. bassiana, seva 2121 in 2122, Slika 1).
Doslej je večina avtorjev testirala komercialne insekticide na podlagi entomopatogenih gliv (EPF) ali pa komercializirane izolate EPF proti jajčecem in/ali mušicam (odraslim osebkom) PVM (Cuthbertson in sod., 2014b; Gargani in sod., 2013; Woltz in sod., 2015), z izjemo Naranjo-Lázaro in sod. (2014), ki so testirali nekomercialne izolate EPF Isaria fumosorosea Wize in Metarhizium anisopliae (Metchnikoff) Sorokin proti odraslim mušicam. Cuthbertson in sod. (2014b), Woltz in sod. (2015) in Naranjo-Lázaro in sod. (2014) so poročali, da lahko s pršenjem EPF dosežemo značilno povečanje smrtnosti mušic. Izolati glive $I$. fumosorosea Pf21, Pf17 in Pf15 so povzročili 85, 60 oz. 58 \% smrtnost 12. dan PI (Naranjo-Lázaro in sod., 2014). Bioinsekticid Naturalis (0,3 \% raztopina) je povzročil $44 \%$ smrtnost mušic sedmi dan PI (Cuthbertson in sod., 2014b). Žal pa v teh člankih ne poročajo o vplivu EPF na bube, zato je primerjava rezultatov naših poskusov $\mathrm{Z}$ objavljenimi rezultati problematična. Če vseeno primerjamo vpliv gliv na izleganje bub $\mathrm{z}$ vplivom na odrasle osebke, vidimo, da imajo glive večji vpliv na smrtnost odraslih osebkov (smrtnost med 50 in $85 \%$ ) kot na izleganje bub (zmanjšanje izleganja bub za 15 do $21 \%$ ). Dodatno smo v tej raziskavi opazili značilen posredni učinek na odrasle osebke prek izračuna parametra 'dolgoživost mušic'. Tako se zdi, da so odrasli osebki bolj dovzetni za glivične okužbe kot bube. Skladno s tem, naši izsledki kažejo na vprašljivo uspešnost potencialne uporabe EPF za obdelavo tal $\mathrm{V}$ sadovnjakih $\mathrm{z}$ namenom zmanjšanja populacije PVM.

Poskus določanja $\mathrm{IC}_{50}$ izleganja bub PVM Z namakanjem bub v suspenzijo konidijev gliv $M$. brunneum (1154 in 1868) in B. bassiana (2121), je bil neuspešen. Značilno manjše izleganje mušic je bilo opaženo pri več različnih koncentracijah konidijev ob različnih časih PI, vendar ta odziv ni bil odvisen od koncentracije (Slika 3). To je verjetno najlaže pripisati kratkotrajnosti razvojnega stadija bube (Cini in sod., 2012). 


\section{SKLEPI}

Ugotovili smo, da preizkušane glive značilno vplivajo na izleganje bub PVM. Značilno zmanjšanje izleganja smo opazili pri EPF $M$. brunneum in B. bassiana (Naturalis), ne pa tudi pri talnih glivah iz rodov Clonostachys in Trichoderma. Primerjava objavljenih rezultatov $\mathrm{z}$ rezultati pridobljenimi $\mathrm{v}$ tej študiji kaže, da imajo določeni mikrobni bioinsekticidi in trenutno nekomercialni izolati EPF $\mathrm{v}$ nadzorovanih razmerah večji vpliv na smrtnost mušic vrste $D$. suzukii, $\mathrm{v}$ primerjavi $\mathrm{z}$ nanosom na bube. Posledično bi bilo priporočljivo usmeriti več raziskav v testiranje (neznanih) EPF izolatov proti odraslim mušicam.

\section{ZAHVALA}

Zahvaljujemo se dr. Maarten De Grootu za konstruktivno kritiko rokopisa. Raziskava je bila delno financirana $\mathrm{s}$ strani Programske skupine Kmetijskega inštituta Slovenije Agrobiodiverziteta (P4-0072) in Javne agencije za raziskovalno dejavnost RS (J4-7162). Pisanje rokopisa je bilo financirano $\mathrm{s}$ pomočjo EU FP 7 projekta CropSustaIn (FP7-REGPOT-CT2012-316205). Omemba komercialnih imen bioinsekticidov je namenjena izključno raziskovalnim ciljem in ne pomeni odobritve ali priporočila Kmetijskega inštituta Slovenije.

\section{VIRI}

Bohinc, T., Trdan, S. 2014. Zatiranje plodove vinske mušice (Drosophila suzukii [Matsumura], Diptera, Drosophilidae) s poudarkom na okoljsko sprejemljivih načinih. Acta agriculturae Slovenica, 103, 2: 323-329. doi:10.14720/aas.2014.103.2.17

Bruck, D. J., Bolda, M., Tanigoshi, L., Klick, J., Kleiber, J., DeFrancesco, J., Spitler, H. (2011). Laboratory and field comparisons of insecticides to reduce infestation of Drosophila suzukii in berry crops. Pest Management Science, 67(11), 1375-85. doi:10.1002/ps.2242

Chabert, S., Allemand, R., Poyet, M., Eslin, P., \& Gibert, P. (2012). Ability of European parasitoids (Hymenoptera) to control a new invasive Asiatic pest, Drosophila suzukii. Biological Control, 63(1), 40-47. doi:10.1016/j.biocontrol.2012.05.005

Cini, A., Anfora, G., Escudero-Colomar, L. A., Grassi, A., Santosuosso, U., Seljak, G., \& Papini, A. (2014). Tracking the invasion of the alien fruit pest Drosophila suzukii in Europe. Journal of Pest Science, 87, 559-566. doi:10.1007/s10340-0140617-z

Cini, A., Ioriatti, C., \& Anfora, G. (2012). A review of the invasion of Drosophila suzukii in Europe and a draft research agenda for integrated pest management. Bulletin of Insectology, 65(1), 149160.

Cuthbertson, A. G. S., Blackburn, L. F., \& Audsley, N. (2014). Efficacy of Commercially Available
Invertebrate Predators against Drosophila suzukii. Insects, 5(4), 952-960. doi:10.3390/insects5040952

Cuthbertson, A. G. S., Collins, D. A., Blackburn, L. F., Audsley, N., \& Bell, H. A. (2014). Preliminary screening of potential control products against Drosophila suzukii. Insects, 5(2), 488-498. doi:10.3390/insects5020488

Gabarra, R., Riudavets, J., Rodríguez, G. a., PujadeVillar, J., \& Arnó, J. (2015). Prospects for the biological control of Drosophila suzukii. BioControl, 60(3), 331-339. doi:10.1007/s10526014-9646-z

Gaddum, J. H. (1948). Probit Analysis. Nature, 161(4090), 417-418. doi:10.1038/161417a0

Gargani, E., Tarchi, F., Frosinini, R., Mazza, G., \& Simoni, S. (2013). Notes on Drosophila suzukii Matsumura (Diptera Drosophilidae): field survey in Tuscany and laboratory evaluation of organic products. Redia. Retrieved from http://crajournals.cineca.it/index.php/redia/article/view/769

Lee, J. C., Bruck, D. J., Dreves, A. J., Ioriatti, C., Vogt, H., \& Baufeld, P. (2011). In Focus: Spotted wing drosophila, Drosophila suzukii, across perspectives. Pest Management Science, 67(11), 1349-1351. doi:10.1002/ps.2271

Motulsky, H. (1995). Intuitive biostatistics. Oxford: Oxford University Press. 
Naranjo-Lázaro, J. M., Mellín-Rosas, M. A., GonzálezPadilla, V. D., Sánchez-González, J. A., MorenoCarrillo, G., \& Arredondo-Bernal, H. C. (2014). Susceptibility of Drosophila suzukii Matsumura (Diptera: Drosophilidae) to Entomophatogenic Fungi. Southwestern Entomologist, 39(1), 201-203. doi:10.3958/059.039.0119

Razinger, J., Lutz, M., Schroers, H. J., Palmisano, M., Wohler, C., Urek, G., \& Grunder, J. (2014b). Direct plantlet inoculation with soil or insect-associated fungi may control cabbage root fly maggots. Journal of Invertebrate Pathology, 120, 59-66. doi:10.1016/j.jip.2014.05.006

Razinger, J., Lutz, M., Schroers, H.-J., Urek, G., \& Grunder, J. (2014a). Evaluation of Insect Associated and Plant Growth Promoting Fungi in the Control of Cabbage Root Flies. Journal of Economic Entomology, 107(4), 1348-1354. Journal Article. doi:10.1603/EC14004

Rossi Stacconi, M. V., Buffington, M., Daane, K. M., Dalton, D. T., Grassi, A., Kaçar, G., Anfora, G. (2015). Host stage preference, efficacy and fecundity of parasitoids attacking Drosophila suzukii in newly invaded areas. Biological Control, 84, 28-35. doi:10.1016/j.biocontrol.2015.02.003

Rota-Stabelli, O., Blaxter, M., \& Anfora, G. (2013). Drosophila suzukii. Current Biology, 23(1), R8-R9. doi:10.1016/j.cub.2012.11.021

Van Timmeren, S., \& Isaacs, R. (2013). Control of spotted wing drosophila, Drosophila suzukii, by specific insecticides and by conventional and organic crop protection programs. Crop Protection, 54, 126-133. doi:10.1016/j.cropro.2013.08.003

Walse, S. S., Krugner, R., \& Tebbets, J. S. (2012). Postharvest treatment of strawberries with methyl bromide to control spotted wing drosophila, Drosophila suzukii. Journal of Asia-Pacific Entomology, 15(3), 451-456. doi:10.1016/j.aspen.2012.05.003

Woltz, J. M., Donahue, K. M., Bruck, D. J., \& Lee, J. C. (2015). Efficacy of commercially available predators, nematodes and fungal entomopathogens for augmentative control of Drosophila suzukii. Journal of Applied Entomology, n/a-n/a. doi:10.1111/jen.12200 